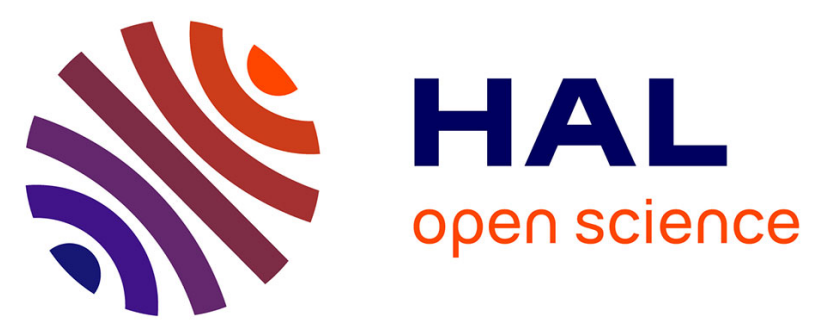

\title{
Modelling mechanical properties of spruce and Douglas fir timber by means of X-ray and grain angle measurements for strength grading purpose
}

Joffrey Viguier, Damien Bourreau, Jean-François Bocquet, Guillaume Pot, Laurent Bléron, Jean-Denis Lanvin

\section{To cite this version:}

Joffrey Viguier, Damien Bourreau, Jean-François Bocquet, Guillaume Pot, Laurent Bléron, et al.. Modelling mechanical properties of spruce and Douglas fir timber by means of X-ray and grain angle measurements for strength grading purpose. European Journal of Wood and Wood Products, 2017, 75 (4), pp.527-541. 10.1007/s00107-016-1149-4 . hal-01530963

\section{HAL Id: hal-01530963 \\ https://hal.science/hal-01530963}

Submitted on 1 Jun 2017

HAL is a multi-disciplinary open access archive for the deposit and dissemination of scientific research documents, whether they are published or not. The documents may come from teaching and research institutions in France or abroad, or from public or private research centers.
L'archive ouverte pluridisciplinaire HAL, est destinée au dépôt et à la diffusion de documents scientifiques de niveau recherche, publiés ou non, émanant des établissements d'enseignement et de recherche français ou étrangers, des laboratoires publics ou privés.

\section{다(1)(2)}

Distributed under a Creative Commons Attribution - ShareAlikel 4.0 International 
Modelling mechanical properties of spruce and Douglas fir timber by means of X-ray and grain angle measurements for strength grading purpose

Joffrey Viguier ${ }^{1 *}$, Damien Bourreau ${ }^{2}$, Jean-François Bocquet ${ }^{1}$, Guillaume Pot $^{3}$, Laurent Bléron $^{1}$, Jean-Denis Lanvin ${ }^{4}$

${ }^{1 *}$ Université de Lorraine, ENSTIB/LERMAB, 27 rue Philippe SEGUIN, BP1041, F88051 Epinal Cedex 9, France

${ }^{2}$ LERFOB, UMR INRA-ENGREF, Research Centre of Nancy, 54280 Champenoux, France

${ }^{3}$ LaBoMaP, Groupe Matériaux et Usinage Bois, Arts \& Métiers ParisTech, rue Porte de Paris, F-71250 Cluny, France

${ }^{4}$ FCBA, Allée de Boutaut, F-33000 Bordeaux, France

Corresponding author : joffrey.viguier@gmail.com

\begin{abstract}
This study proposes a model using data from a scanner (X-ray and grain angle measurements) to perform strength grading. The research also includes global measurements of modulus of elasticity (obtained by vibrations and ultrasound methods), static bending stiffness and bending strength of 805 boards of Douglas fir and 437 boards of spruce. This model can be used in an industrial context since it requires low computational time. The results of this study show that the developed model gives better results than the global non-destructive measurements of the elastic modulus commonly used in the industry. It also shows that this improvement is particularly higher in the case of Douglas fir than for spruce. The comparison has been made on both the quality of the mechanical properties assessment and on the improvement of the grading process according to the European standards by using different index.
\end{abstract}




\section{List of symbols :}

l

$t$

$h$

$f$

$t_{\text {sound }}$

$\rho$

$G$

$a_{\rho}, b_{\rho}$

$\rho_{c w}, \rho_{k n o t}$

$f_{1}, f_{2}$

$K D R$

$\theta$

$H(\theta)$

$(E I)_{e f f}$

$x, y$

$E(x, y)$

$E_{m, g}$

$E_{\text {sound }}$

$E_{v i b}$

$E_{\text {model }}$

IPMOE $E_{\text {model }}$

$\sigma_{m}$

$\sigma_{\text {model }}$

IPMOR ${ }_{\text {model }}$
Length of the board

Thickness of the board

Height of the board

First natural frequency under longitudinal vibration

Travel time of the ultrasonic wave

Board average density

Grey level of X-Ray Images

Linear calibration coefficients of local density measurement

Clear wood and knot density

Parameters of the KDR calculation

Knot Depth Ratio : ratio between the knot's thickness and the thickness of the board

Projection of the grain angle on the surface of the board

Function linking mechanical properties and grain angle

Effective bending stiffness

Local coordinates in length and height of the board

Local modulus of elasticity calc. on basis of measured singularities

Global MOE assessed by static bending with a span of 18 times the height of the board

MOE calc. on basis of the speed of an ultrasonic wave

MOE calc. on basis of the first natural frequency under longitudinal vibration

MOE calc. on basis of the proposed model for the same span as the actual static test

Indicating property of the MOE calc. on basis of the proposed model for the full-length of the board

Experimental bending strength with a span of 18 times the height of the board

Bending strength calc. on basis of the proposed model for the same span as the actual static test

Indicating property of the MOR calc. on basis of the proposed model for the full-length of the board

\section{Introduction}

The wood material presents a very high variability in terms of mechanical properties. This variability comes from several factors. In particular, many studies have shown the existing correlation between density and mechanical properties (Rohanovà et al., 2011; Wang et al., 2008; Hanhijarvi et al., 2008; Johansson et al., 1992). The density can vary across species and between individuals of the same species and even within the same tree. Moreover, for structural application, local singularities in timber are present such as knots, grain angle or the presence of juvenile or reaction wood. These singularities have a strong influence on the final mechanical properties of the board. Indeed, several studies (Hanhijarvi et al., 2008; Piter et al., 2004; Riberholt and Madsen, 1979) showed that the first stage of the failure of timber occurs most likely in areas where the knots are concentrated (in fact the presence of the largest knot or group of knots) and that the knottiness can be a good indicator of the mechanical properties. The grain angle also explains the reduction of wood strength (Brannstrom et al., 2008; Bano et al., 2011; Olsson et al., 2013; Viguier et al., 2015), in particular the deviation of the fibres around knots, which is the result of simultaneous secondary growth of the trunk and branch. The variation in grain angle 
influences the mechanical properties of timber, as the maximum strength of timber occurs when the load is parallel to the fibres direction and decreases non-linearly when the angle formed by the fibres increases (Bergman et al., 2010).

However, since 2012, on the European market, wood used for structural purpose has to be graded according to strength and it has to be CE marked to ensure the designer that the product meets the standards specifications. This grading must guarantee three properties : density, modulus of elasticity (MOE) and bending strength sometimes called modulus of rupture (MOR). Because of the wide variability, the grading is based on socalled characteristic values that are fifth percentile for density and MOR and mean value for the MOE. There are two ways to perform the grading : visual or machine grading. It is well known that visual methods lead to a large proportion of downgraded boards (Roblot et al., 2008).

Main techniques used so far to perform machine grading are based on the existing correlation between the modulus of elasticity and bending strength. The modulus of elasticity can be determined on a global or local level but it is known that local MOE measures may give better predictors of bending strength than what global MOE does (Oscarsson et al., 2014). The methods used on those two levels are :

- on a global level : these techniques are based on elastic modulus estimation by vibration methods (van de Kuilen, 2002; Biechele et al., 2011) or using its relationship with the velocity of a wave (Rajeshwar et al., 1997). These methods are extremely dependent on the correlation between MOE and MOR and only take partially into consideration local singularities (Olsson et al., 2012).

- on a local level : the local estimation of the modulus of elasticity can be obtained with flat wise bending machines (machines stress rating), which consist of deflecting a piece of timber over a given span at a certain interval (Biechele et al., 2011). There are also ways to measure singularities that affect the mechanical properties such as knot (Roblot et al., 2010; Oh et al., 2009) or grain deviation (Simonaho et al., 2004). The local modulus of elasticity can be calculated using grain angle information and mechanical modelling (Olsson et al., 2013). There are also machines on the market today that combine vibration methods and X-ray measurements.

The aim of this study is to propose a fast way to use local data (X-ray measurements and grain angle) to perform strength grading while remaining feasible in an industrial context, meaning at high-speed (about $200-300 \mathrm{~m} / \mathrm{min}$ ). This is done by means of mechanical modelling on the basis of non-destructive measurements. Moreover, the proposed model is analyzed on the basis of the prediction quality of the mechanical properties and on the results of the grading process according to EN 14081 (CEN, 2011; CEN, 2013; CEN, 2012a; CEN, 2009). The proposed grading method is then compared to existing methods on two species used in timber structure in France (spruce and Douglas fir).

\section{Materials and methods}

\subsection{Sampling}

The sample is composed of 437 spruce boards (Picea abies) and 805 Douglas fir boards (Pseudotsuga menziesii) sawn from approximatively 45 years old tree harvested in French forest. The different boards were dried to about $12 \%$ of moisture content. The mean moisture content is respectively equal to $11.3 \%$ and $11.45 \%$ for spruce and Douglas fir. Three different sections were chosen : 40x100 mm² (137 and 235 for spruce and Douglas fir respectively), $50 \times 150 \mathrm{~mm}^{2}$ (150 and 278) and $65 \times 200 \mathrm{~mm}^{2}$ (150 and 292). The length of all boards is about $4 \mathrm{~m}$. 


\section{$2.2 \quad$ Non-destructive measurements}

\subsubsection{Stiffness measurements}

Two different non-destructive methods were used to estimate the modulus of elasticity of the boards on a global level.

- One using the relationship between the speed of an ultrasonic wave along the board and its Young's modulus. The modulus of elasticity is then calculated using equation 1.

- One other using the relationship between the resonance frequency of the boards under longitudinal vibration and its Young's modulus. The modulus of elasticity is then calculated using equation 2 .

$$
E_{\text {sound }}=\rho \times\left(\frac{l}{t_{\text {sound }}}\right)^{2}
$$

Where $: E_{\text {sound }}$ : estimation of the MOE, $\rho:$ density, $l:$ board's length, $t_{\text {sound }}:$ travel time of the ultrasonic wave

$$
E_{v i b}=4 \rho f^{2} l^{2}
$$

Where : $E_{v i b}$ : estimation of the MOE, $\rho$ : density, $l:$ board's length, $f:$ first natural frequency under longitudinal vibration

\subsubsection{Local measurements}

All boards were passed through a scanner dedicated to mechanical grading to obtain different local data such as density, grain angle and knottiness. The following coordinate system has been considered : $\mathrm{x}$-direction along the length and y-direction along the heigth.

\section{Density measurement}

In addition to a global weighing and measuring that gives the average density, the density of boards was measured locally. This measurement is performed by a scanner equipped with an X-rays imaging system. Assuming that the grey levels of thereby provided images are proportional to the acquired corresponding light intensities, they can easily and accurately be converted into local density maps. Under this condition, the Beer-Lambert's law can be applied to determine the density for each pixel of the densities maps (Kim et al., 2006). The final expression of the local density $\rho(x, y)$, averaged through the thickness of the board, is given by equation 3 , where t represents the thickness of the board, $a_{\rho}$ and $b_{\rho}$ are linear calibration coefficients, $\mathrm{G}$ is the corresponding image pixel's grey level, and $\mathrm{x}$ and $\mathrm{y}$ are the local coordinates. The resolution in $\mathrm{x}$ and $\mathrm{y}$ directions is, respectively, 10 and 2 $\mathrm{mm}$.

$$
\rho(x, y) \times t(x, y)=a_{\rho} \times \ln (G(x, y))+b_{\rho}
$$

The actual values of $a_{\rho}$ and $b_{\rho}$ depend on several factors, but can easily be determined by scanning and weighing a batch of boards. These two parameters are in fact the linear regression coefficients between mean value of $\ln (G)$ of the boards, calculated on the images and their mean densities multiplied by their respective thickness.

\section{Grain angle measurement}

The grain angle was measured using the tracheid's effect (Olsson et al., 2013; Simonaho et al., 2004), by projecting a laser line on the surface of the boards. Due to the wood's anisotropic light diffusion properties, the observed pattern on the surface of the board is 
elliptic. The ellipses main axis is oriented in the same direction as the fibre orientation, or more exactly in the same direction as the projection of the grain angle on the surface of the board. Consequently, the measure of the grain angle can be obtained thanks to a Principal Component Analysis applied on the ellipse binarized image. The evolution of grain angle of the whole surface of each board can be obtained by illuminating the wood surface by laser dots along a line that is perpendicular to the main direction of the board, as shown in Figure 1. The measurement has been made on the two wide faces of each board (not on the narrow faces).

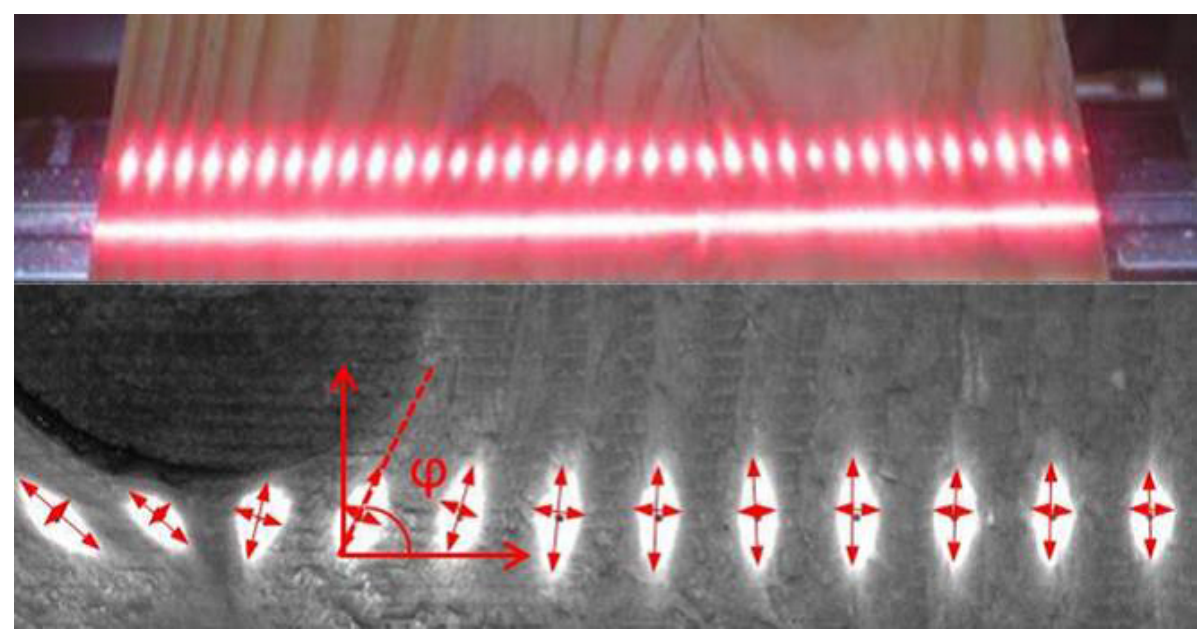

FiguRE 1 - Actual technology used in the scanner (top) and illustration of the grain angle measurements (bottom)

\section{Knottiness calculation}

The characterization of the knottiness was made by calculating the Knot Depth Ratio (KDR). This value represents the local knot thickness divided by the thickness of the board (Oh et al., 2009). The resolution is the same as for the density measurement. This method relies on the fact that the knot density is higher than the clear wood density. The KDR is equal to 0 in clear wood and 1 when at a given position the thickness of the board is composed entirely of knot. The KDR is calculated using equation 4 where $\rho_{c w}$ and $\rho_{k n o t}$ are the clear wood and knot density respectively, $f_{1}$ represents the clear wood density variability within a board $\left(f_{1}=1+\left(\operatorname{std}\left(\rho_{c w}\right)\right) /\left(\operatorname{mean}\left(\rho_{c w}\right)\right)\right)$ and $f_{2}$ is the ratio between $\rho_{k n o t}$ and $\rho_{c w}$. Finally $\rho(x, y)$ is the locally measured density. The $f_{1}$ parameter is useful in order to limit over sensing due to the natural variability of density.

$$
\begin{aligned}
& K D R(x, y)=0 \quad \text { if } \quad \rho(x, y)<f_{1} \times \rho_{c w} \\
& K D R(x, y)=\frac{\rho(x, y)-\rho_{c w}}{\rho_{k n o t}-\rho_{c w}} \text { if } f_{1} \times \rho_{c w}<\rho(x, y)<f_{2} \times \rho_{c w} \\
& K D R(x, y)=1 \quad \text { if } \quad \rho(x, y)>f_{2} \times \rho_{c w}
\end{aligned}
$$

In order to determine those parameters $\left(f_{1}, f_{2}, \rho_{c w}\right.$ and $\left.\rho_{k n o t}\right)$ a first image processing step is used to separate knotty areas from clear wood ones. For each board, $\rho_{k n o t}$ can be calculated as the mean of the density measured in knotty areas, $\rho_{c w}$ as the mean density of clear wood areas and $f_{1}, f_{2}$ are calculated using the previously defined formulas. Finally, the different parameters for each species are taken as the mean of the values found on each board of the studied batches. Knot density is then assumed to be constant and proportional to clear wood density within a batch. 


\section{Illustration of the data obtained from the scanner}

An example of the grain angle and density measurements on a board is shown in Figure 2. This figure shows that because of the density variation there are clear wood areas where the KDR values are not equal to 0. Nevertheless, the values of the KDR are very low in those areas, and have only a slight influence on the outcome of the modelling. A strong grain angle deviation around the knots is also observable.

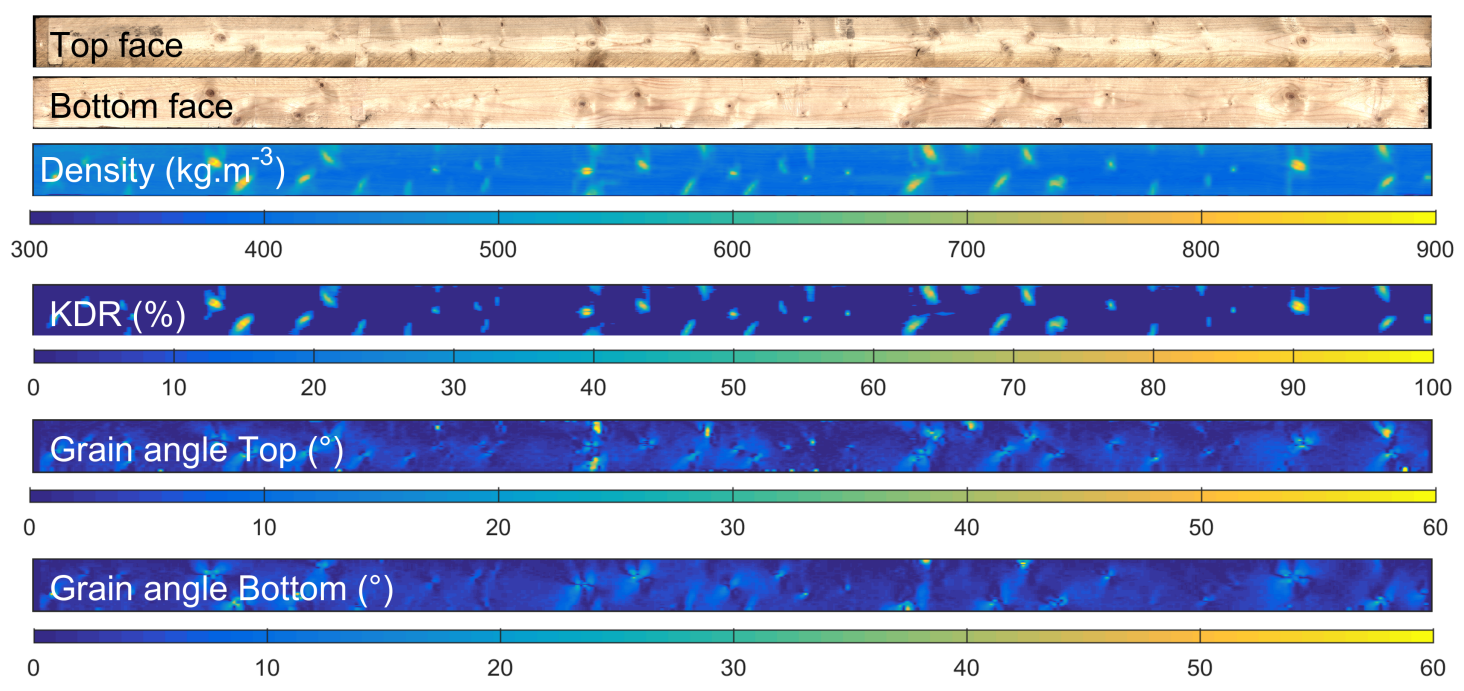

FiguRE 2 - Photographs of top and bottom faces and model's input data maps; from top to bottom, density, Knot Depth Ratio and grain angle of top and bottom faces 


\subsection{Destructive tests}

The different boards have been destructively tested in bending. These destructives tests have been performed according to EN 408 (CEN, 2012b). The critical cross-section was chosen visually and placed between the loading heads. Bending tests were performed using a distance equal to 18 times the specimen's height between the supports and 6 times between the loading heads. The bending test performed was an edgewise bending test and the tension edge was selected at random. The global modulus of elasticity is calculated using equation 5 where $b$ and $h$ are respectively the thickness and the height of boards, $a$ is equal to $6 \times h$ and $l$ is the span. $F_{2}-F_{1}$ is an increment of load on the regression line (on the load vs displacement curve) with a correlation coefficient of 0.99 or better, and $w_{2}-w_{1}$ is the increment of global displacement corresponding to $F_{2}-F_{1}$. The bending strength is calculated according to equation 6 where $F_{\max }$ is the maximum load during the bending test. The boards having a moisture content in the range $8 \%$ to $18 \%$, their modulus of elasticity has been adjusted to $12 \%$ moisture content according to EN 384 (1\% change for every percentage point difference in moisture content). For bending strength no adjustment has been made according to EN 384 .

$$
\begin{aligned}
E_{m, g} & =\frac{3 a l^{2}-4 a^{3}}{4 b h^{3} \frac{w_{2}-w_{1}}{F_{2}-F_{1}}} \\
\sigma_{m} & =\frac{3 F_{\max } a}{b h^{2}}
\end{aligned}
$$

According to EN 384 (CEN, 2010) some adjustments have been made on the modulus of elasticity and bending strength. To determine the sample mean of modulus of elasticity for strength grading purpose, the mean global MOE shall be corrected using equation 7 which includes an adjustment to a pure bending modulus of elasticity. The bending strength is adjusted to boards of $150 \mathrm{~mm}$ height by dividing $\sigma_{m}$ by $k_{h}$ with $k_{h}=\left(\frac{150}{h}\right)^{0.2}$ in order to take into account size effects.

$$
\bar{E}=1.3 \times\left[\sum E_{m, g_{i}} / n\right]-2690
$$

\subsection{Mechanical modelling}

The following model is based on the theory of linear elasticity considering each pixel as a single element with its own mechanical properties, depending on the measured singularities ( $\rho$, KDR, grain angle). Since the destructive tests have been made according to EN 408, the span depends on the height of each board. Consequently, for certain boards (those with a lower height), the span is not equal to their full length. For the calibration of the model (part 2.4.1 and 2.4.2), the considered length depends on the height of the boards (18 times the specimen's height between the supports and 6 times between the loading heads). In other terms, only a part of the different images is considered. However, for strength grading purpose (part 2.4.3) the estimation of the mechanical properties must be representative of the entire board, in this case the full-length $(4 \mathrm{~m})$ is considered.

\subsubsection{Estimation of the MOE}

\section{Estimation of the local modulus of elasticity}

The first step is to assign a modulus of elasticity $E(x, y)$ to each element of the board. $E(x, y)$ has been chosen according to the local density and the local grain angle. Concerning the dependency on the local density, a linear relationship between $E(x, y)$ and $\rho(\mathrm{x}, \mathrm{y})$ has been chosen. In addition, the influence of the local grain angle is taken into account by 
using a function based on the Hankinson formula (Bergman et al., 2010). Finally, the local modulus of elasticity $E(x, y)$ is calculated using equation 8 .

$$
E(x, y)=\left(g_{1}+g_{2} \times\left(\rho(x, y)-g_{3}\right)\right) \times \frac{H\left[\theta_{t o p}(x, y)+H\left[\theta_{b o t}(x, y)\right.\right.}{2}
$$

Where :

- $g_{1} g_{2}$ and $g_{3}$ are the coefficient of the linear relationship between $\mathrm{E}(\mathrm{x}, \mathrm{y})$ and $\rho(x, y)$

- $\theta_{\text {top }}(x, y)$ and $\theta_{b o t}(x, y)$ are the values of grain angle measured respectively on top and bottom faces

- $H(\theta)$ is a function giving the reduction factor between the modulus of elasticity parallel to the grain (which is in practice the modulus of elasticity determined by the linear relationship with the density) and the modulus of elasticity at the measured grain angle value

The $H(\theta)$ function is given by equation 9 where $E_{0}$ is the modulus of elasticity determined thanks to the linear relationship with the density, $\mathrm{k}$ a coefficient representing the ratio $E_{90} / E_{0}$ with $E_{90}$ the modulus of elasticity perpendicular to the grain, and n a constant.

$$
H(\theta)=\frac{E(\theta)}{E_{0}}=\frac{k}{\sin ^{n}(\theta)+k \cos ^{n}(\theta)}
$$

Note that the reduction due to the grain angle is taken as the mean of the reduction induced by the grain angle on each wide face of the boards. Those different steps on a spruce board are given in Figure 3.
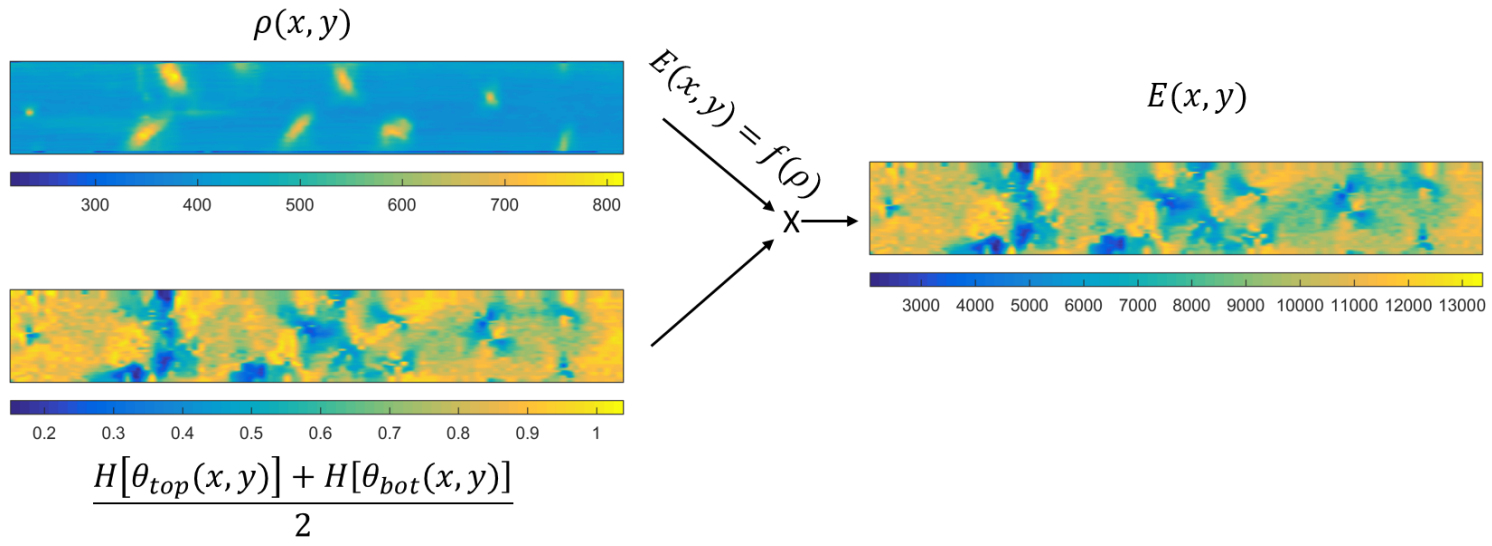

FigURE 3 - Illustration of the local modulus of elasticity computation along the beam

\section{Estimation of the effective bending stiffness}

The effectiveness of the calculation of the effective bending stiffness to predict the bending strength of timber has already been proven in Olsson et al. (2013). It was therefore chosen to be used. The presence of knots within the thickness of the boards is taken into account by reducing the local thickness using equation 10 . The $\alpha$ parameter has been added in order to allocate a given weight to the knottiness. Considering this reduction of thickness and the previous local modulus of elasticity, an effective bending stiffness $(E I)_{e f}$ can now be calculated for each section (i.e along the total height at a given $\mathrm{x}$ position) along the sollicited part of the board, using equation 11.

$$
t(x, y)=1-\alpha \times K \operatorname{KDR}(x, y)
$$




$$
(E I)_{e f}(x)=\sum_{j=1}^{n_{\text {elements }}}\left(E(x, j) I(x, j)+E(x, j) A(x, j) a(x, j)^{2}\right)
$$

Where $E(x, j), A(x, j), I(x, j)$ and $a(x, j)$ are respectively : the modulus of elasticity, the area, the second moment of area, and the distance from the neutral fibre of each element at a given x position. $n_{\text {elements }}$ is the total number of elements along the total height of each section and $j$ is the index of the elements along the y direction. The effective bending stiffness is calculated for each segment $i$ of the board along the $\mathrm{x}$ direction. The length of those segments corresponds to the resolution of the images along the $\mathrm{x}$ axis.

\section{Estimation of the MOE}

In this section, the deflection at mid-span in the case of a four point bending test $\left(v\left(\frac{l}{2}\right)\right)$ of the degraded boards is calculated in order to obtain $E_{\text {model }}$ which can be assimilated to an equivalent of $E_{m, g}$. The deflection at mid-span $\left(v\left(\frac{l}{2}\right)\right)$ of the degraded boards can be calculated using the principle of virtual work. See equation 12 where $M_{f}(i)$ is the bending moment during a four point bending test, $M_{v}(i)$ is the bending moment induced by an unitary load at mid-span, $(E I)_{e f}(i)$ is the effective bending stiffness of each segment $i$ and $\Delta l$ the length of each segment $(\Delta l=1 \mathrm{~cm}$ which corresponds to the resolution of the images along $\mathrm{x}$ direction). These variables are described in Figure 4.

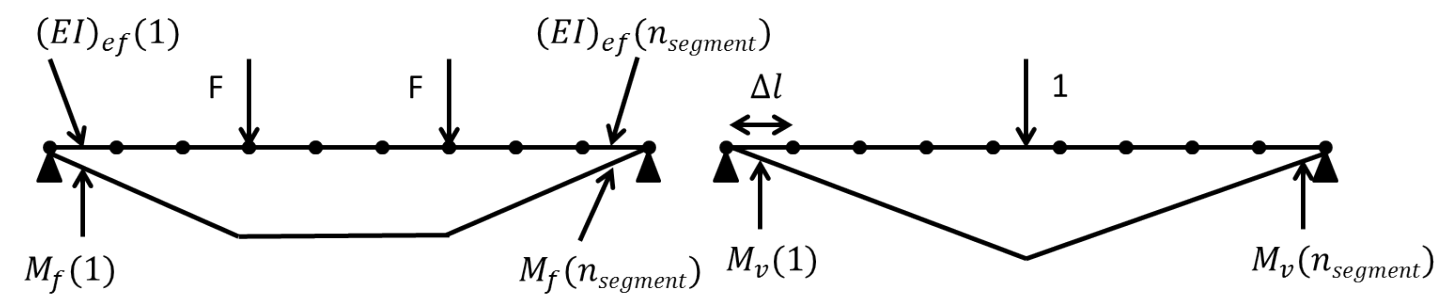

Figure 4 - Definition of the variables used in the MOE estimation

$$
v\left(\frac{l}{2}\right)=\sum_{i=1}^{n_{\text {segment }}} \frac{M_{f}(i) M_{v}(i)}{(E I)_{e f}(i)} \Delta l
$$

The modulus of elasticity is then calculated by application of beam theory in 4 point bending using equation 13 where $\mathrm{F}$ is the load which induced the previous bending momentum $M_{f}, 1$ is the span, I the second moment of inertia of the actual board and the deflection term is the one calculated with the principle of virtual work on the degraded board (equation 12).

$$
E_{\text {model }}=\frac{23 F l^{3}}{648 I v\left(\frac{l}{2}\right)}
$$

\subsubsection{Estimation of the MOR}

In the following part, note that the difference of rupture behaviour existing in compression and tension is not taken into account. Making this differentiation could be dangerous since after the grading process it is not possible to know which side of the different boards will be solicited during their use. 


\section{Stress calculation}

The normal stress at each element is calculated using equation 14 where $E(x, y)$ is the local modulus of elasticity defined previously $M_{f}$ is the bending momentum, $a(x, y)$ is the distance between the neutral axis of each element and the neutral axis of the board and $h_{e}$ is the height of each element ( $h_{e}$ is actually constant and equal to $2 \mathrm{~mm}$ which is the resolution of the images along the y direction). Note that the term $a(x, y)$ is variable along the $\mathrm{x}$ direction (at a given y position of the board) since the neutral axis of the board is dependent on the KDR due to the reduced thickness of the degraded board.

$$
\sigma(x, y)=\frac{E(x, y) a(x, y) M_{f}(x)}{(E I)_{e f}(x)}+\frac{E(x, y)\left(h_{e} / 2\right) M_{f}(x)}{(E I)_{e f}(x)}
$$

\section{Admissible strength estimation}

An estimation of the admissible strength of each element is calculated according to equation 15. It depends on the modulus of elasticity (linearly with the $\mathrm{K}$ parameter) and the grain angle using the same $\mathrm{H}$ function as in equation 9 with a different set of parameters, since the grain angle influence is not the same, according to the studied property (Bergman et al., 2010).

$$
\sigma_{\text {lim }}(x, y)=K \times E(x, y) \times \frac{H\left[\theta_{t o p}(x, y)+H\left[\theta_{b o t}(x, y)\right.\right.}{2}
$$

\section{Estimation of the MOR}

Finally, the estimation of the modulus of rupture consists in finding the bending momentum for which the calculated stress $\sigma(x, y)$ of a $\mathrm{N}$ percentage of the total elements (those between the supports) reaches the admissible strength $\sigma_{l i m}(x, y)$. The modulus of rupture is then calculated using equation 16 where $M_{f_{l i m}}$ is the ultimate bending momentum, $I$ the modulus of inertia of the actual board and $h$ is the height of the board.

$$
\sigma_{\text {model }}=\frac{M_{f_{l i m}}}{I / h / 2}
$$

\section{Model parameters}

Several parameters were defined to take into account the different singularities; the optimal values obtained for those parameters are the results of an optimization using the simplex method; the objective function is the minimum of the root mean square error between the prediction and the destructive results. Those parameters needed to be optimized in conditions as close as possible to reality, so the actual test have been modeled. However, in practice for strength grading, indicating properties representative of the entire board must be defined.

\subsubsection{Calculation of indicating properties}

\section{IPMOE $E_{\text {model }}$}

The calculation of IPMOE model follows exactly the same steps as those described previously to calculate $E_{\text {model }}$ but in this case the span is the entire board (i.e the length is equal to $4 \mathrm{~m}$ ) and not only the part of the boards that was actually loaded.

\section{IPMOR model}

The calculation of the IPMOR model is based on the same principle used in the calculation of $\sigma_{\text {model }}$, but this time the entire board is considered. Since the percentage of the broken surface (N, table 3) is optimized for a length equal to 18 times the height of the board, $M_{f_{l i m}}$ is calculated within a window (with a length equal to 18 times the height 
of the board) moving along the entire board. The bending momentum is constant in each window. The calculation of IPMOR $R_{\text {model }}$ is then conducted with the minimum of $M_{f_{l i m}}$ from all windows. The stress fields (for the board presented in Figure 2) for the actual bending momentum and for a constant bending momentum can be seen in Figure 5 .
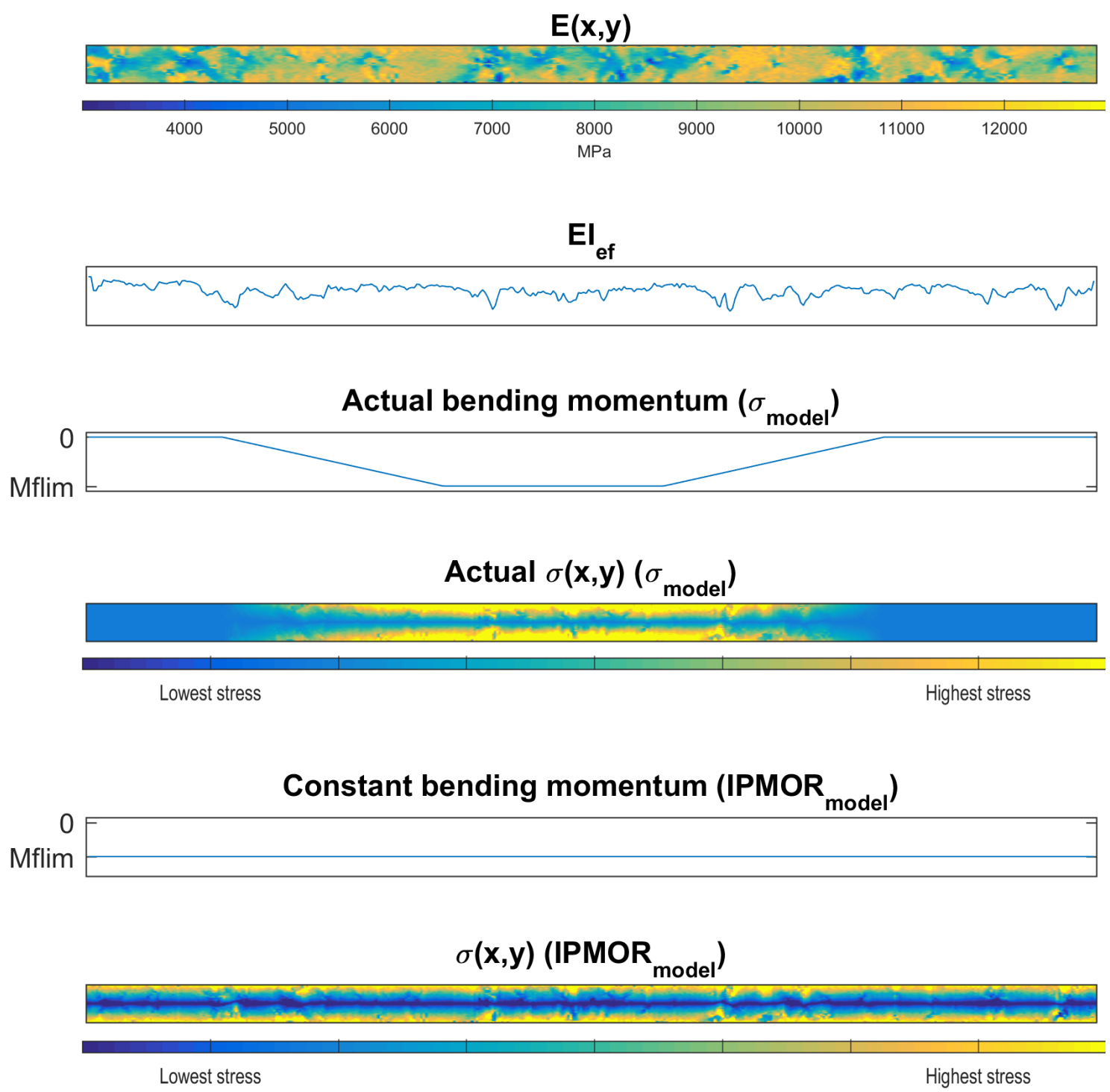

Figure 5 - From top to bottom : local modulus of elasticity; effective bending stiffness along the board; bending momentum used for the $\sigma_{\text {model }}$ calculation; normal stress under the bending momentum of the actual four points bending test; bending momentum used for the IPMOR model determination and normal stress under the constant bending momentum. The differents fields correspond to the data of the board presented in Figure 2.

\subsection{Machine grading and efficiency}

Strength grading was made according to EN 14081 standards. Two commonly used grade combinations were chosen, C30/C18/Reject and C24/Reject. The indicating properties for the vibration and ultrasound methods are taken as the MOE predictions described previously (directly equal to $E_{v i b}$ and $E_{\text {sound }}$ ). 
The starting point of the method described in EN 14081 is to build a size matrix which is a double entry table comprising optimal grade vs. assigned grade. In order to obtain the optimal grading, all the pieces shall be sorted into the highest possible grades that are graded together, such that they meet the required values for the grade. Optimal grading is made on the basis of the mechanical properties obtained during the four point bending test according to the algorithm described in EN 14081-2 (part 6.2.4.5). The assigned grade of each board is obtained by following the method described in EN 14081-2 as well (part 6.2.4.6).

Basically, the method consists in finding indicative properties threshold values; boards with indicating properties higher than these thresholds must fulfill the requirements of the limits defined for each grade in EN 338. This standard requires that the fifth percentiles of density, the fifth percentiles of modulus of rupture $f_{05}$ and the average modulus of elasticity $(\bar{E})$ of the selected boards must be above the given limits in EN 338 for the grade considered.

Moreover, grading has to fulfil the cost matrix method defined in EN 14081-2. This method requires in particular the construction of the size matrix. An example is given in Table 1 (a). The terms on the diagonal represent well graded boards, i.e boards assigned (with the machine) to the same grade as in the case of optimal grading. The upper part of the matrix represents downgraded boards, i.e boards that are assigned to a lower grade than their optimal grade. Then, the lower part of the matrix represents the upgraded boards, i.e boards that are graded in a higher grade than their optimal grade. Finally, a global cost matrix is calculated by dividing each cell of the size matrix by the total number of boards on the assigned grade and by multiplying it by the corresponding term in a so called elementary cost matrix. The upper part of the elementary cost matrix describes the cost of downgraded boards and the lower part the safety risk of upgraded boards. Since upgraded boards migth represent a danger, the number of upgraded boards is limited by the previously cited standards by considering that the settings of the machine are valid if the terms of the lower part of the global cost matrix are lower than 0.2. These matrixes are described in Table 1.

In order to characterize the performance of the studied grading machines, different index were calculated :

- The index of accuracy is equal to the well graded boards' percentage $\left(\frac{75+17+5}{201} \times\right.$ $100=48 \%$ in the case of Table 1 ).

- Selling price : represents the ratio between the selling prices of the batch of boards graded by machine and the batch of boards optimally graded. The following prices were taken as 100, 200, 220 and 240 euros.m ${ }^{-3}$ respectively for Reject, C18, C24, and C30 quality. Those prices are representative of the French market price and are based on surveys of industrial partners. The Selling price is equal to $\frac{78 \times 240+48 \times 220+75 \times 100}{171 \times 240+18 \times 220+12 \times 100} \times$ $100=80 \%$ in the case of Table 1 .

- The index of efficiency is the application of the method described by Roblot et al.(2013).

To compute the index of efficiency, the first step is to compute a so-called efficiency size matrix which presents the repartition of the boards between grades, but wrongly upgraded boards are moved to the correct grade. A global efficiency matrix is then built based on the method used for the global cost matrix described in EN 14081. The difference stands in the calculation of the efficiency elementary cost matrix. In this case the efficiency elementary cost matrix is computed by dividing the elementary cost matrix of EN 14081 by the maximum value of the upper part of the diagonal. This maximum is 4.5 and corresponds to a C50 board rejected from C14 grade. The complementary to one is finally taken in order to get higher weights for well graded boards and lower for downgraded boards. The different matrixes calculated according to Roblot et al. and EN 14081 are given in Table 1. The 
index of efficiency is the sum of global efficiency matrix divided by the number of grades $\frac{1+0.55+0.60+0.41+0+0.15}{3} \times 100=90.33 \%$ for Table 1 data.

$\begin{array}{cccc} & \text { C30 } & \text { C24 } & \text { Reject } \\ \text { C30 } & 75 & 26 & 70 \\ \text { C24 } & 1 & 17 & 0 \\ \text { Reject } & 2 & 5 & 5\end{array}$

(a) Size matrix (EN 14081)

$\begin{array}{cccc} & \text { C30 } & \text { C24 } & \text { Reject } \\ \text { C30 } & 0 & 0.29 & 1.33 \\ \text { C24 } & 0.83 & 0 & 1.01 \\ \text { Reject } & 2.22 & 1.11 & 0\end{array}$

(c) Elementary cost matrix (EN 14081)

$\begin{array}{cccc} & \text { C30 } & \text { C24 } & \text { Reject } \\ \text { C30 } & 0 & 0.16 & 1.24 \\ \text { C24 } & 0.01 & 0 & 0 \\ \text { Reject } & 0.06 & 0.12 & 0\end{array}$

(e) Global cost matrix (EN 14081)

$\begin{array}{cccc} & \text { C30 } & \text { C24 } & \text { Reject } \\ \text { C30 } & 75 & 26 & 70 \\ \text { C24 } & - & 18 & 0 \\ \text { Reject } & - & - & 12\end{array}$

(b) Efficiency size matrix

$\begin{array}{cccc} & \text { C30 } & \text { C24 } & \text { Reject } \\ \text { C30 } & 1 & 0.93 & 0.70 \\ \text { C24 } & - & 1 & 0.78 \\ \text { Reject } & - & - & 1\end{array}$

(d) Efficiency elementary cost matrix

$\begin{array}{cccc} & \text { C30 } & \text { C24 } & \text { Reject } \\ \text { C30 } & 1 & 0.55 & 0.60 \\ \text { C24 } & - & 0.41 & 0 \\ \text { Reject } & - & - & 0.15\end{array}$

(f) Global efficiency cost matrix

TABLE 1 - Cost matrix method and computation of the index of efficiency

\section{Results and discussions}

\subsection{Destructives tests}

The measured and calculated properties of the different boards for each species, i.e density, modulus of elasticity and bending strength are presented in Table 2. Mechanical and physical properties are higher for Douglas fir than for spruce. The mean density is on average $19 \%$ higher for Douglas fir than for spruce, nearly the same percentage can be observed on the $E_{m, g}$ and the $5 \%$ percentile of $\sigma_{m}$ is $24 \%$ higher for Douglas fir than for spruce. The correlations between density and both $E_{m, g}$ and $\sigma_{m}$ for the two species are in the same range (slightly lower in the case of density and MOR for Douglas fir). The coefficient of determination between $E_{m, g}$ and $\sigma_{m}$ is considerably higher for spruce than for Douglas fir (0.71 compared to 0.58).

\begin{tabular}{cccccccc|ccc} 
& & Min & Mean & Max & $5 \%$ percentile & StD & CV $(\%)$ & $\mathrm{R}^{2}$ & $E_{m, g}$ & $\sigma_{m}$ \\
\hline \multirow{3}{*}{ Spruce } & $\sigma_{m}(\mathrm{MPa})$ & 10.0 & 31.3 & 70.1 & 15.0 & 11.4 & 36.5 & $\rho$ & 0.48 & 0.28 \\
& $E_{m, g}(\mathrm{MPa})$ & 3756 & 8800 & 19849 & 5190 & 2615 & 29.7 & $E_{m, g}$ & - & 0.71 \\
& $\rho\left(\mathrm{kg} . \mathrm{m}^{-3}\right)$ & 286 & 394 & 582 & 327 & 48.0 & 12.2 & & & \\
\hline \multirow{3}{*}{ Douglas fir } & $\sigma_{m}(\mathrm{MPa})$ & 9.5 & 34.1 & 76.7 & 19.7 & 11.6 & 34 & $\rho$ & 0.53 & 0.23 \\
& $E_{m, g}(\mathrm{MPa})$ & 4693 & 10809 & 20073 & 7326 & 2434 & 22.5 & $E_{m, g}$ & - & 0.58 \\
& $\rho\left(\mathrm{kg} . \mathrm{m}^{-3}\right)$ & 384 & 487 & 639 & 426 & 40.1 & 8.2 & & & \\
\hline
\end{tabular}

TABLE 2 - Minimum, mean, maximum, $5 \%$ percentiles values, standard deviations, coefficient of variation, and coefficient of determination for different properties measured

\subsection{Non-destructive measurements}

\subsubsection{Density measurements}

The comparison between the average density measured by simply measuring and weighing the boards and the average density measured by X-ray scanning highlights the very 
good accuracy of this method. Indeed the coefficients of determination are respectively equal to 0.99 and 0.96 for spruce and Douglas fir. The accuracy is slightly better in the case of spruce despite the fact that the calibration has been carried out on the two species.

\subsubsection{Knotiness measurements}

The first image processing used to compute the KDR gives the following results : the average clear wood density is equal to $383 \mathrm{~kg} \cdot \mathrm{m}^{-3}$ and $475 \mathrm{~kg} \cdot \mathrm{m}^{-3}$ respectively for spruce and Douglas fir and $770 \mathrm{~kg} \cdot \mathrm{m}^{-3}$ and $817 \mathrm{~kg} \cdot \mathrm{m}^{-3}$ concerning the average knot density. The mean values of the $f_{1}$ parameters (the ones used in the analytical model) are nearly the same for spruce as for Douglas fir (1.11 and 1.13 respectively). The $f_{2}$ parameters are quite different (2.03 and 1.75) between the two species showing that the difference between clear wood density and knot density is higher in the case of spruce than for Douglas fir. Finally the mean KDR is higher in the case of Douglas fir (0.43) than for spruce (0.32) and indicates the potential higher nodosity of Douglas fir compared to spruce.

\subsubsection{Stiffness measurements}

The vibratory method estimates highly accurately the MOE for both spruce and Douglas fir with a high coefficient of determination ( 0.85 and 0.80 respectively). Concerning the correlation with the MOR, the results are consistent with those observed with destructive values, i.e. a better correlation for spruce than for Douglas fir (0.58 compared to 0.44). It seems that the ultrasound method gives lower results independently of the species. Indeed, the coefficients of determination between $E_{\text {sound }}$ and $E_{m, g}$ are respectively equal to 0.76 and 0.68 for spruce and Douglas fir. The ones between $E_{\text {sound }}$ and $\sigma_{m}$ are respectively equal to 0.48 and 0.34 . Those results are consistent with a previous study (Wang et al., 2008).

\subsection{Mechanical modelling}

\subsubsection{Mechanical properties prediction}

As stated earlier, different parameters have been defined to consider the different singularities depending on the species; the optimal values obtained for those parameters are described in Table 3. The parameters of the linear relationship between density and modulus of elasticity might appear different depending on the species but they describe nearly the same relationship. Concerning the $\alpha$ parameters which in fact reflect the influence of the knottiness, it seems to take a greater value for the bending strength prediction. Concerning the parameters of grain angle they are consistent with the literature. The $\mathrm{K}$ parameters represent the relationship between MOE and MOR for wood without defects, it can be considered acceptable for example that for a board with a MOE equal to 10000 $\mathrm{MPa}$ the corresponding MOR is equal to approximatively $50 \mathrm{MPa}$. Concerning the last parameter $\mathrm{N}$, it is there expressed as a percentage of the «broken »surface based on the total surface of the board. It corresponds to a surface equal to approximatively 38 and 49 $\mathrm{cm}^{2}$ for spruce and Douglas fir respectively.

The relationships between $E_{\text {model }}$ (Eq. 13) and the measured global MOE as defined in equation 5, and between $\sigma_{\text {model }}$ (Eq. 16) and the measured MOR (Eq. 6) are presented in Figure 6. The coefficient of determination between $E_{\text {model }}$ and $E_{m, g}$ is lower than the one between $E_{v i b}$ and $E_{m, g}$ but the correlation is quite good and even better than the one observed for the ultrasound method $E_{\text {sound }}$ for both spruce and Douglas fir. The root mean square error between $E_{\text {model }}$ and $E_{m, g}$ is equal to 1188 (13\% of the mean value) and $1224 \mathrm{MPa}$ (11\% of the mean value) respectively for spruce and Douglas fir. Concerning the MOR, it can be seen that taking into account the different measured singularities 


\begin{tabular}{lc|cc|cc} 
& & \multicolumn{2}{|c}{ Spruce } & \multicolumn{2}{c}{ Douglas fir } \\
& & $E_{\text {model }}$ & $\sigma_{\text {model }}$ & $E_{\text {model }}$ & $\sigma_{\text {model }}$ \\
\hline Multiplying factor between E and $\sigma$ (Eq. 15) & $\mathrm{K}$ & \multicolumn{3}{c|}{4.87} & \multicolumn{2}{c}{4.67} \\
Percentage of broken surface (\%) & $\mathrm{N}$ & \multicolumn{2}{c|}{0.93} & \multicolumn{2}{c}{1.17} \\
& $g_{1}$ & 15898 & & 13722 & \\
Parameters of the relationship between E and $\rho$ (Eq. 8) & $g_{2}$ & 35169 & & 35555 \\
& $g_{3}$ & 0.52 & & 0.48 \\
Thickness reduction coefficient (Eq. 10) & $\alpha$ & 0.88 & 0.89 & 0.70 & 0.84 \\
Parameters of Hankinson formula (Eq. 9) & $\mathrm{k}$ & 0.015 & 0.02 & 0.010 & 0.03 \\
& $\mathrm{n}$ & 1.95 & 2.26 & 2.20 & 2.22
\end{tabular}

TABLE 3 - Model parameters for the two species

improves a lot the prediction. The results are better for spruce than for Douglas fir ; it can be explained by the higher intrinsic correlation between $\rho$ and $\sigma_{m}$ and $E_{m, g}$ and $\sigma_{m}$ (Table 2 ). The root mean square error between $\sigma_{\text {model }}$ and $\sigma_{m}$ is equal to $6.5 \mathrm{MPa}$ ( $21 \%$ of the mean value) and $7.9 \mathrm{MPa}$ ( $22 \%$ of the mean value) respectively for spruce and Douglas fir. Concerning the computational time, it is about $72 \mathrm{~s}$ for the batch of spruce boards and 137s for the batch of Douglas fir boards on a personal computer.
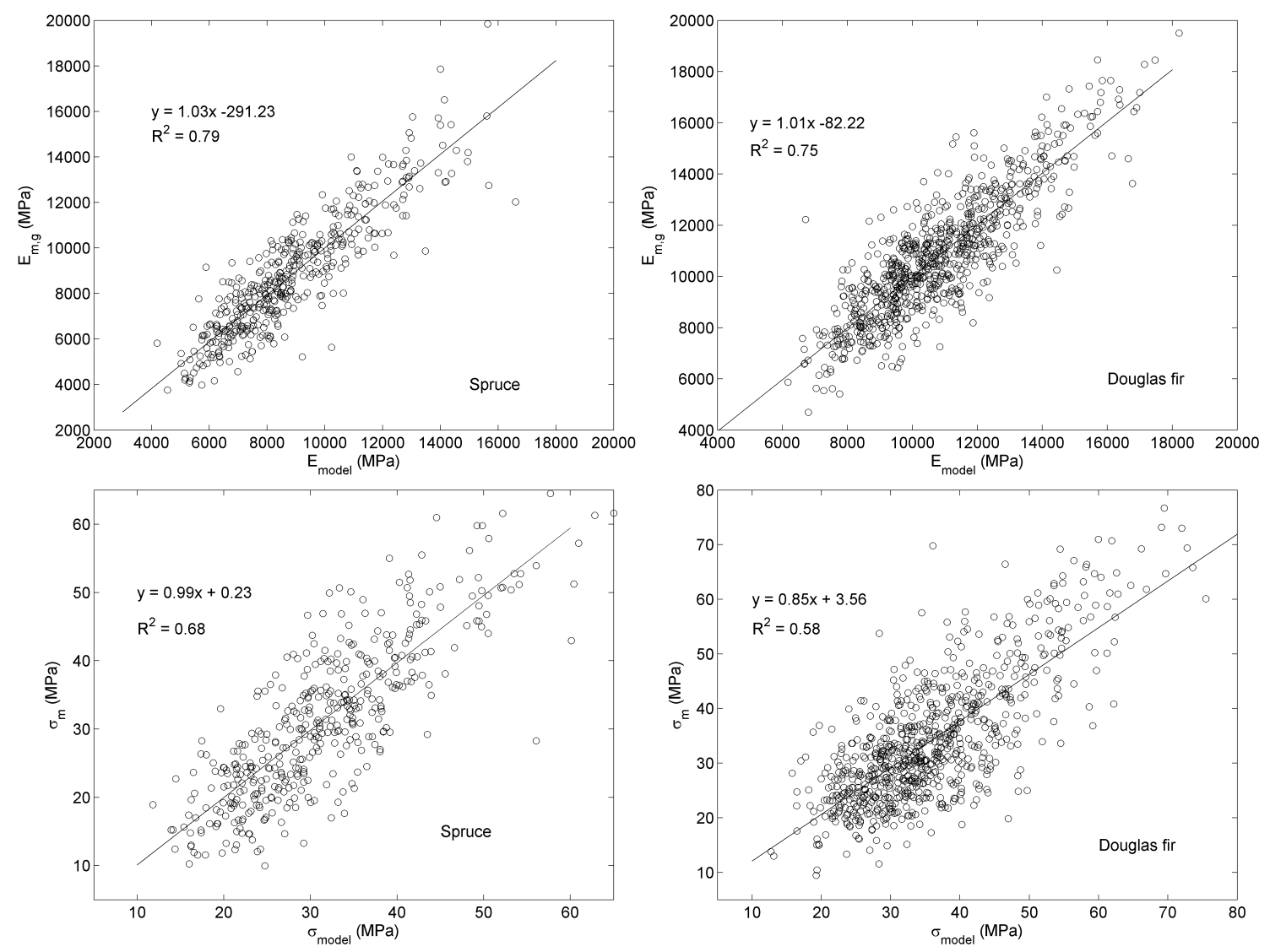

Figure 6 - Comparison of predicted and tested values of the modulus of elasticity and bending strength in the case of spruce and Douglas fir.

\subsubsection{Indicating properties}

The coefficients of determination between $I P M O E_{\text {model }}$ and $E_{m, g}$ are respectively equal to 0.78 for spruce and 0.74 in the case of Douglas fir. The ones between $I P M O R_{\text {model }}$ and $\sigma_{m}$ are respectively equal to 0.66 for spruce and 0.53 for Douglas fir. The coefficients of 
determination are lower in the case of the two indicating properties :

- 0.78 compared to 0.79 and 0.74 compared to 0.75 for $E_{m, g}$

- 0.66 compared to 0.68 and 0.53 compared to 0.58 for $\sigma_{m}$

Those results are due to the fact that the computation of the Indicating Properties includes parts of the boards that weren't actually sollicited during the four point bending tests.

\subsection{Grading efficiency}

Grading results for the different methods and the C24/Reject combination in the case of Douglas fir are presented in Table 4. As a reminder when grading by machines, the required characteristic value on the 5th percentile bending strength must be divided by the factor $k_{v}$ which is equal to 1.12 for grades with $f_{m, k}$ equal or less than $30 \mathrm{MPa}$ and 1 for other grades (EN 14081-2 part 6.2.2 and EN 384). The required average modulus of elasticity is equal to the required average MOE of the grade times 0.95 (EN 14081-2 part 6.2.4.5). By taking into account those adjustements, the requirements for the $\mathrm{C} 24$ grade are respectively equal to $21.4 \mathrm{MPa}, 10450 \mathrm{MPa}$ and $350 \mathrm{~kg}^{-3}$ for the 5 th percentile MOR, the mean MOE and the 5th percentile MOR. The MOR is clearly the discriminating property in this combination, so it explains why the methods with the higher correlation with the MOR give the better results.

\begin{tabular}{ccccccccc} 
& \multicolumn{2}{c}{ Optimal } & \multicolumn{2}{c}{ Model } & \multicolumn{2}{c}{ Vibration } & \multicolumn{2}{c}{ Ultrasound } \\
& C24 & Reject & C24 & Reject & C24 & Reject & C24 & Reject \\
n & $764(95 \%)$ & $41(5 \%)$ & $610(76 \%)$ & $195(24 \%)$ & $558(69 \%)$ & $247(31 \%)$ & $424(53 \%)$ & $381(47 \%)$ \\
5th percentile MOR & $\mathbf{2 1 . 4 6}$ & 11.06 & $\mathbf{2 1 . 4 4}$ & 16.10 & $\mathbf{2 1 . 4 4}$ & 17.49 & $\mathbf{2 1 . 5 0}$ & 18.50 \\
Mean MOE & 10950 & 8165 & 11510 & 8615 & 11812 & 8540 & 12242 & 9213 \\
5th percentile $\rho$ & 427 & 412 & 436 & 415 & 445 & 410 & 454 & 415 \\
IP MOE threshold & - & - & 7752 & - & 9644.2 & - & 10515 & - \\
IP MOR threshold & - & - & 27.8 & - & - & - & -
\end{tabular}

TABLE 4 - Grading results in the case of Douglas fir for the C24/Reject combination

Grading results of the different methods presented in this study and for the chosen grade combinations are given in Figure 7. On the basis of the optimal grading (i.e. made according to the destructive test results) Douglas fir has better mechanical properties than spruce; this is consistent with the observation of the previously established characteristics values. The studied spruce batch has a lower proportion of C30 boards than the Douglas fir batch; the grading process by machine gives almost the same proportion of $\mathrm{C} 30$ boards for both species. As an example, for the model and the C30/C18/Reject combination, $32 \%$ of spruce timber is graded C30 compared to $39 \%$ actually present in the batch, while for the case of Douglas fir the proportion is only $26 \%$ compared to $70 \%$. Whatever the machines used, spruce is better valued than Douglas fir. This difference is much less visible for lower grade but this fact is visible by considering the average efficiency of all machines and all the grade combination, that is about $96 \%$ for spruce and just over $90 \%$ for Douglas. The correlation of the ultrasound method with MOE and MOR were lower, the results show that it is also on average the least efficient machine to perform mechanical grading on the two batches of boards.

Table 5 shows the gain (in \%) observed by using the developed model in comparison to the other two methods studied in terms of efficiency, accuracy and selling prices. For all three criteria and any combination of grade tested, the use of the model is always an improvement in the case of Douglas fir, while the improvement is only consistently greater in terms of accuracy for grade combination containing C30 in the case of spruce. Note that despite this difference, the use of the proposed model is still favourable to grade a larger number of boards in higher grade. The fact that the improvement is greater in the case of Douglas fir is due to the fact that the consideration of the local defects in the case 
of Douglas fir greatly improves the correlation with $\sigma_{m}$ compared to the methods that measure a global MOE while in the case of spruce, these methods take advantage of the better correlation between $E_{m, g}$ and $\sigma_{m}$.

\begin{tabular}{ccccc}
\hline \multicolumn{5}{c}{ Efficiency } \\
& C30/C18/Reject & C24/Reject \\
Vibration & Spruce & Douglas & Spruce & Douglas \\
Ultrasound & $+0.85 \%$ & $+0.22 \%$ & $-0.17 \%$ & $+0.46 \%$ \\
\hline \multicolumn{5}{c}{ Accuracy } \\
& C30/C18/Reject & C24/Reject \\
& Spruce & Douglas & Spruce & Douglas \\
Vibration & $+1.24 \%$ & $+9.8 \%$ & $-3.20 \%$ & $+8.08 \%$ \\
Ultrasound & $+7.76 \%$ & $+30.06 \%$ & $+19.41 \%$ & $+28.43 \%$ \\
& \multicolumn{5}{c}{ Selling price } \\
\hline & C30/C18/Reject & C24/Reject \\
& Spruce & Douglas & Spruce & Douglas \\
Vibration & $-3.84 \%$ & $+1.23 \%$ & $+0.67 \%$ & $+4.07 \%$ \\
Ultrasound & $+1.18 \%$ & $+3.47 \%$ & $+17.71 \%$ & $+14.53 \%$
\end{tabular}

TABLE 5 - Gain or loss (in \%) observed using the proposed model compared to existing methods 

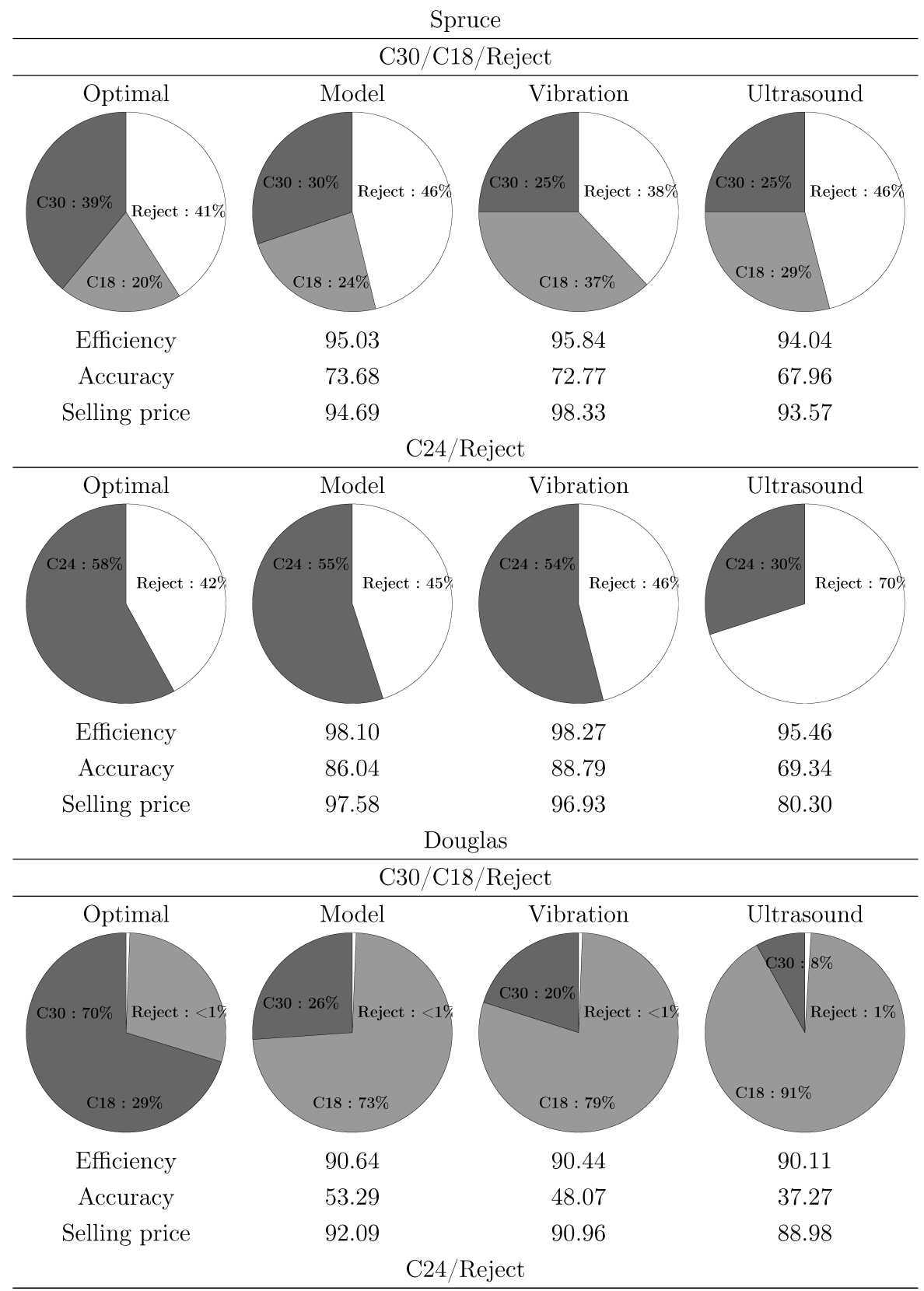

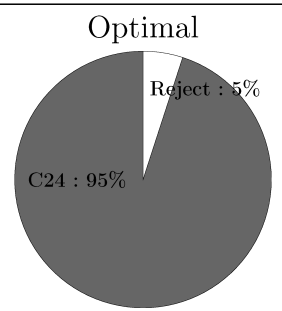

Efficiency

Accuracy

Selling price

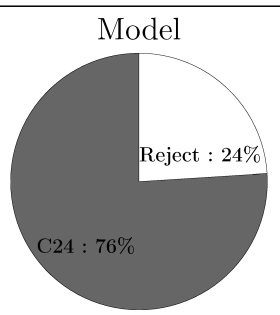

91.14

76.89

89.27

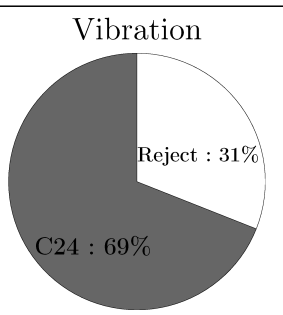

90.72

70.68

85.64

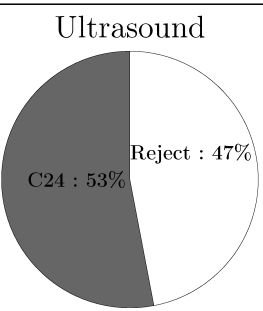

90.15

55.03

76.30

FIGURE 7 - Strength grading results of every machine and every grade combination tested for Spruce (top) and Douglas fir (bottom) 


\section{Conclusion}

This study shows that it is possible to develop a mechanical model using local information (measured by a scanner dedicated to mechanical grading) to perform strength grading in an industrial context instead of global information. Indeed, the model allows to handle a speed of about 1600 meters per minute (with a personal computer) and is therefore not a limiting factor when comparing this rate to the acquisition speed of the scanner which is approximatively 200 meters per minute. In addition, this method gives better results (in terms of efficiency, accuracy and economic valorisation) than two commonly used methods which consist of a non-destructive measurement of the global elastic modulus. It was also shown that the application of this method is more efficient in the case of Douglas fir than for spruce, and that this difference is probably due to the lower natural correlation between the MOE and MOR, and also that bigger knots are present in the case of Douglas fir. Taking into account Douglas fir local singularities strongly improves the correlation between the MOR prediction and the actual MOR which leads to better results on the strength grading. In order to improve the models performance, other kind of singularities, such as juvenile or compression wood, could be taken into account. For example the linear relationship between the density and the modulus of elasticity could be changed in areas where there is juvenile wood which has a lower modulus of elasticity than mature wood (Moore et al., 2009).

\section{Ascknowledgment}

The present study is supported by the French National Research Agency through the ANR CLAMEB project (ANR-11-RMNP-0015). The conduct of this work was made possible through the support from the following organizations : FCBA where the destructive tests were made, LaBoMaP for the non-destructive tests part and finally LERFoB for the sampling. LERMAB is supported by the French National Research Agency through the Laboratory of Excellence ARBRE (ANR-12-LABXARBRE-01).

\section{Références}

Bano, V., Arriaga, F., Soilan, A., and Guaita, M. (2011). Prediction of bending load capacity of timber beams using a finite element method simulation of knots and grain deviation. Biosystems engineering, 109(4) :241-249.

Bergman, R., Cai, Z., Carll, C., Clausen, C., Dietenberger, M., Falk, R., Frihart, C., Glass, S., Hunt, C., and Ibach, R. (2010). Wood handbook: Wood as an engineering material. Forest Products Laboratory.

Biechele, T., Chui, Y. H., and Gong, M. (2011). Comparison of NDE techniques for assessing mechanical properties of unjointed and finger-jointed lumber. Holzforschung, 65(3) :397-401.

Brannstrom, M., Manninen, J., and Oja, J. (2008). Predicting the strength of sawn wood by tracheid laser scattering. Bioresources, 3(2):437-451.

CEN (2009). EN 14081-4 Strength graded structural timber with rectangular cross section Part 4 : Machine grading - Grading machine settings for machine controlled systems.

CEN (2010). EN 384 Structural timber - Determination of characteristic values of mechanical properties and density.

CEN (2011). EN 14081-1 Strength graded structural timber with rectangular cross section Part 1 : General requirements. 
CEN (2012a). EN 14081-3 Strength graded structural timber with rectangular cross section - Part 3 : machine grading; additional requirements for factory production control.

CEN (2012b). EN 408 Structural timber and glued laminated timber - Determination of some physical and mechanical properties.

CEN (2013). EN 14081-2 Strength graded structural timber with rectangular cross section Part 2 : Machine grading; additional requirements for initial type testing.

Hanhijarvi, A., Ranta-Maunus, A., and Turk, G. (2008). Potential of strength grading of timber with combined measurement techniques. Combigrade-project VTT Publications 568 .

Johansson, C., Brundin, J., and Gruber, R. (1992). Stress grading of Swedish and German timber. A comparison of machine stress grading and three visual grading systems. Technical Report SP Report, Swedish National Testing and Research Institute.

Kim, G.-M., Lee, S.-J., and Lee, J.-J. (2006). Development of portable X-ray CT system 1-evaluation of wood density using X-ray radiography. Journal of the Korean Wood Science and Technology, 34(1) :15-22.

Moore, J., Achim, A., Lyon, A., Mochan, S., and Gardiner, B. (2009). Effects of early respacing on the physical and mechanical properties of Sitka spruce structural timber. Forest Ecology and Management, 258(7) :1174-1180.

Oh, J.-K., Shim, K., Kim, K.-M., and Lee, J.-J. (2009). Quantification of knots in dimension lumber using a single-pass X-ray radiation. Journal of wood science, 55(4) :264-272.

Olsson, A., Oscarsson, J., Johansson, M., and Kallsner, B. (2012). Prediction of timber bending strength on basis of bending stiffness and material homogeneity assessed from dynamic excitation. Wood Science and Technology, 46(4) :667-683.

Olsson, A., Oscarsson, J., Serrano, E., Källsner, B., Johansson, M., and Enquist, B. (2013). Prediction of timber bending strength and in-member cross-sectional stiffness variation on the basis of local wood fibre orientation. European Journal of Wood and Wood Products, 71(3) :319-333.

Oscarsson, J., Olsson, A., and Enquist, B. (2014). Localized modulus of elasticity in timber and its significance for the accuracy of machine strength grading. Wood and Fiber Science, 46(4) :489-501.

Piter, J., Zerbino, R., and Blass, H. (2004). Machine strength grading of Argentinean Eucalyptus grandis - Main grading parameters and analysis of strength profiles according to European standards. Holz als Roh- und Werkstoff, 62(1):9-15.

Rajeshwar, B., Bender, D., Bray, D., and McDonald, K. (1997). An ultrasonic technique for predicting tensile strength of Southern Pine lumber. Transactions of the asae, 40(4) :1153-1159.

Riberholt, H. and Madsen, P. (1979). Strength of timber structures, measured variation of the cross sectional strength of structural lumber. Technical Report Report R 114, Structural Research Laboratory, Technical University of Denmark.

Roblot, G., Bléron, L., Mériaudeau, F., and Marchal, R. (2010). Automatic computation of the knot area ratio for machine strength grading of Douglas-fir and Spruce timber. European Journal of Environmental and Civil Engineering, 14(10) :1317-1332.

Roblot, G., Coudegnat, D., Bleron, L., and Collet, R. (2008). Evaluation of the visual stress grading standard on French Spruce (Picea excelsa) and Douglas-fir (Pseudotsuga menziesii) sawn timber. Annals of forest science, 65(8).

Rohanovà, A., Lagana, R., and Babiak, M. (2011). Comparison of non-destructive methods of quality estimation of the construction spruce wood grown in Slovakia. 17th international nondestructive testing and evaluation of wood symposium, Hungary. 
Simonaho, S., Palviainen, J., Tolonen, Y., and Silvennoinen, R. (2004). Determination of wood grain direction from laser light scattering pattern. Optics and lasers in engineering, 41(1) :95-103.

van de Kuilen, J.-W. (2002). Bending strength and stress wave grading of tropical hardwoods. COST E24 Reliability analysis of timber structures, Zurich.

Viguier, J., Jehl, A., Collet, R., Bleron, L., and Meriaudeau, F. (2015). Improving strength grading of timber by grain angle measurement and mechanical modeling. Wood $M a$ terial Science \& Engineering, 10(1) :145-156.

Wang, S.-Y., Chen, J.-H., Tsai, M.-J., Lin, C.-J., and Yang, T.-H. (2008). Grading of softwood lumber using non-destructive techniques. Journal of materials processing technology, 208(1-3) :149-158. 